\title{
Application of high-resolution melting analysis for differentiation of spoilage yeasts
}

\author{
Mine Erdem ${ }^{1}$, Zülal Kesmen ${ }^{1 \star}$, Esra Özbekar ${ }^{1}$, Bülent Çetin ${ }^{2}$, and Hasan Yetim ${ }^{1}$
}

${ }^{1}$ Erciyes University, Faculty of Engineering, Food Engineering Department, Kayseri 38039, Turkey
${ }^{2}$ Ataturk University, Faculty of Agriculture, Food Engineering Department, Erzurum 25240, Turkey

In the article by Erdem et al. published in Journal of Microbiology 2016; 54, 618-625, the figure 1 should be corrected as below.
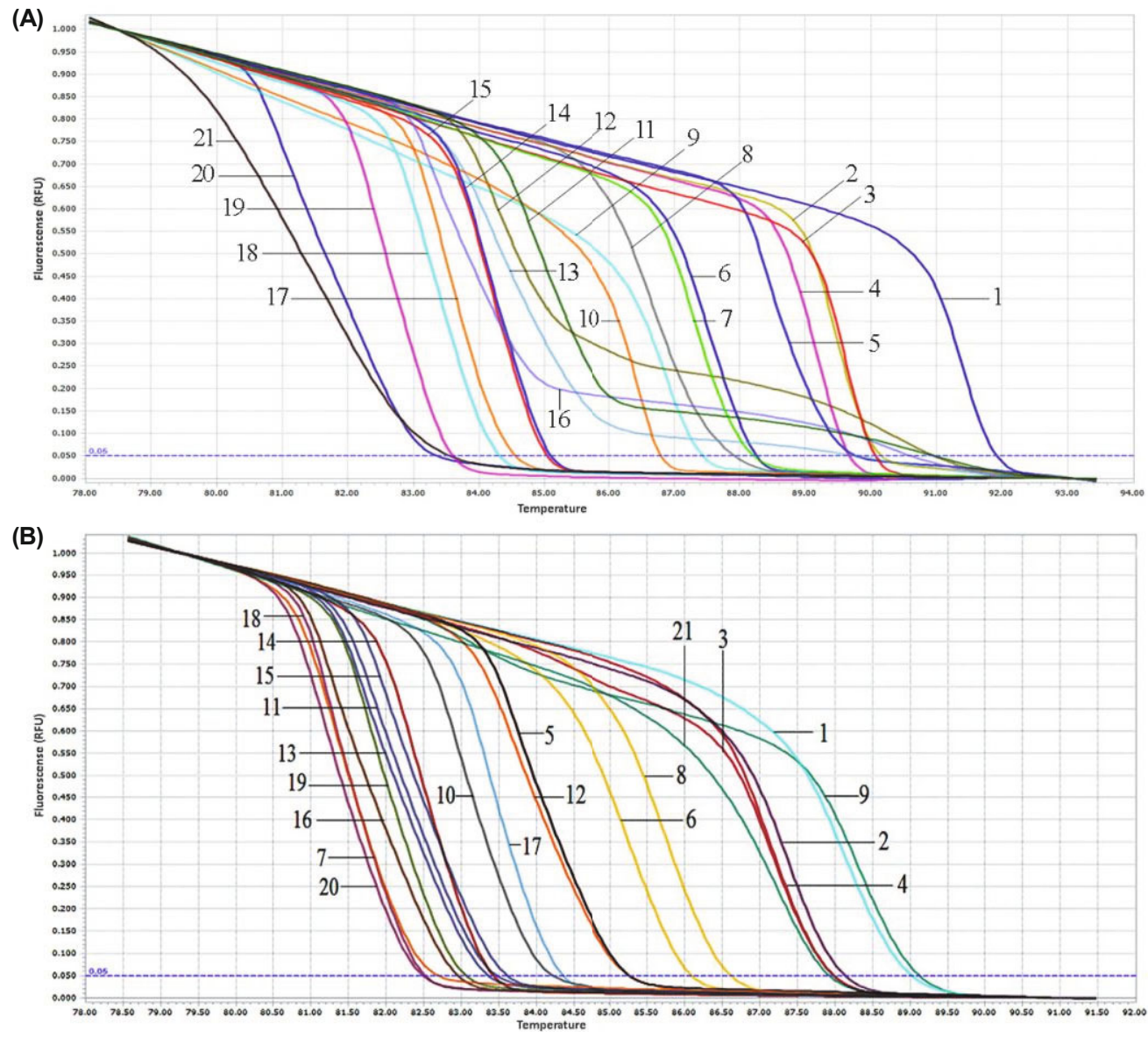